\title{
INCORPORATING A RISK ASSESSMENT PROCEDURE INTO SUBMARINE OUTFALL PROJECTS AND APPLICATION TO PORTUGUESE CASE STUDIES
}

\author{
A. Mendonça ${ }^{1}$, M. A. Losada ${ }^{2}$, S. Solari ${ }^{3}$, M. G. Neves $^{4}$ and M. T. Reis ${ }^{5}$
}

\begin{abstract}
The paper presents a risk assessment methodology for operational limit states of submarine outfall projects that considers: the environmental legislative framework, the climate agents acting on the coastline and prediction of the plume long-term behaviour near the coastline. The probability of operational failure or stoppage is assessed enabling decision on project design alternatives.
\end{abstract}

Keywords: submarine outfalls; risk assessment; climate agents; Monte Carlo

\section{INTRODUCTION}

Submarine outfalls are built for sewage disposal acting as significant elements of an integrated environmental protection system for coastal areas facilitating and/or creating possibilities for economic activities within their immediate context. They are generally found in countries with a densely populated and heavily industrialized coastline. In such contexts, it is almost inevitable for waste to be discharged into estuaries and the sea [Grace, 2009].

For a variety of reasons, an outfall structure may lose its resistance, structural capacity, and/or operational capacity. This total or partial loss may take place at different speeds and be temporary or permanent. The project design should thus be able to assure that the structure will be reliable, functional, and operational. Consequently, values or target levels of these attributes should be specified in the project design phase before the structure is actually built. Evidently, the construction and maintenance costs of the outfall as well as its use and exploitation depend on all of these factors.

Accordingly, the safety, service, and exploitation requirements for the submarine outfall and each of its sections are defined in terms of reliability, functionality, and operationality parameters [ROM $0.0,2002]$.

In each project phase, the structure passes through a sequence of project states characterized by the different values of the project factors. The project of a structure should respond to project requirements, such as the following:

- Spatial (site) and temporal (project phases) domain;

- Requirements for use and exploitation;

- Geometry of the subset and the soil;

- Properties (parameters) of the physical environment and the materials;

- Agents that can interact with the maritime structure and the environment, as well as the specific actions that they carry out.

The project must verify that in every project state, all requirements pertaining to safety, serviceability, as well as use and exploitation are satisfied [ROM 0.0, 2002].

The extreme outcomes of the majority of the agents of the physical environment in a time interval are infrequent occurrences, which must be quantified. They also vary considerably in space. The occurrence and the magnitude or value of the project factor are uncertain from a temporal as well as a spatial perspectives, and one way of dealing with this is by applying probability theory.

The project of a submarine outfall is based on models derived from mathematics and physics. These models are used to design and predict the behaviour of the structure during its useful life and also to quantify the phenomena (physical, chemical, etc.) that affect it. In order to apply these models, it is necessary to have information about the project factors that participate either directly or indirectly in such processes. Consequently, one of the first steps in the project is the definition of the subsets of the structure and of the time intervals for which the project factors can be considered statistically homogeneous and stationary. Their value (magnitude and/or direction) and probability of exceedance are related by means of the distribution function of the random variable.

\footnotetext{
${ }^{1}$ Laboratório Nacional de Engenharia Civil, Av. Brasil 101, 1700-066, Lisbon, Portugal

2 Universidad de Granada. CEAMA, Avda. del Mediterráneo, 5, 18006. Granada, Spain

${ }^{3}$ Universidad de la República, IMFIA-FING, Julio Herrera y Reissing 565, Montevideo, 11300, Uruguay

${ }^{4}$ Laboratório Nacional de Engenharia Civil, Av. Brasil 101, 1700-066, Lisbon, Portugal

${ }^{5}$ Laboratório Nacional de Engenharia Civil, Av. Brasil 101, 1700-066, Lisbon, Portugal
} 
In this regard, this study considers the influence of the physical environment (wave and wind climates) to which the effluent plume will be subject, and which can produce an inefficient plume dispersion and exceedance of threshold values (e.g. coliform concentration) and thus affect submarine outfall operationality.

The risk assessment method outlined aims to specify the probability of operational stoppage/failure due to climate agents, stating/identifying the possible consequences of such a failure or stoppage.

\section{AIM AND SCOPE OF THE PAPER}

The aim of this study is to present a risk assessment methodology to submarine outfall projects that provides information about the conditions of the receiving medium, predicting a long-term behaviour of the plume near the coastline, which allows a multicriteria and an adaptative design of these structures assuring that they will remain operational during their useful life.

The first step is to point out an engineering procedure developed for the specification of the requirements and target design levels of a submarine outfall in the project phase [Mendonça et al., 2012a]. Failure modes and corresponding limit states are identified. A risk assessment procedure is proposed for operational limit states (environmental failure modes) focusing on three main topics: environmental legislative framework, climate agents on the coastline and effluent fate and distribution. The results obtained help identifying the structure's probability of failure or stoppage and the definition of operational target design levels enabling decision on project design alternatives. The developed methodology is illustrated with the submarine outfall of Vale de Faro, Portugal.

\section{TARGET DESIGN LEVELS SPECIFICATION}

The procedure for calculating target design levels determines if a project satisfies the safety, serviceability, and exploitation requirements for the recommended levels of reliability, functionality, and operationality during all of the project phases [Losada and Benedicto, 2005] by defining the general and operational intrinsic natures of the structure [Mendonça et al, 2012a].

\section{General and Operational Intrinsic Nature}

The importance of a maritime structure or one of its sections as well as the economic, social, and environmental impact produced in the case of serious damage or destruction or total loss of service and functionality can be evaluated by means of the general intrinsic nature (GIN) of the structure or any of its sections. The GIN is assessed by selecting the failure mode that gives the highest repercussion value from the principal modes assigned to the ultimate (ULS) and serviceability (SLS) limit states [ROM 0.0, 2002]. The general intrinsic nature of the structure is a function of the economic repercussion index (ERI) and the social and environmental repercussion index (SERI).

The ensuing economic repercussions and the social and environmental repercussions when the maritime structure stops functioning or reduces its operational level are specified by its operational intrinsic nature (OIN). The OIN is evaluated by selecting the operational stoppage mode that gives the minimum operational level. It is then specified in terms of the operational index of economic repercussion (OIER) and the operational index of social and environmental repercussion (OISER).

The methodology applied to submarine outfalls is described in Mendonça et al. (2012a) and resumed in Figure 1.

This study focuses on the operational intrinsic nature of the submarine outfall. 


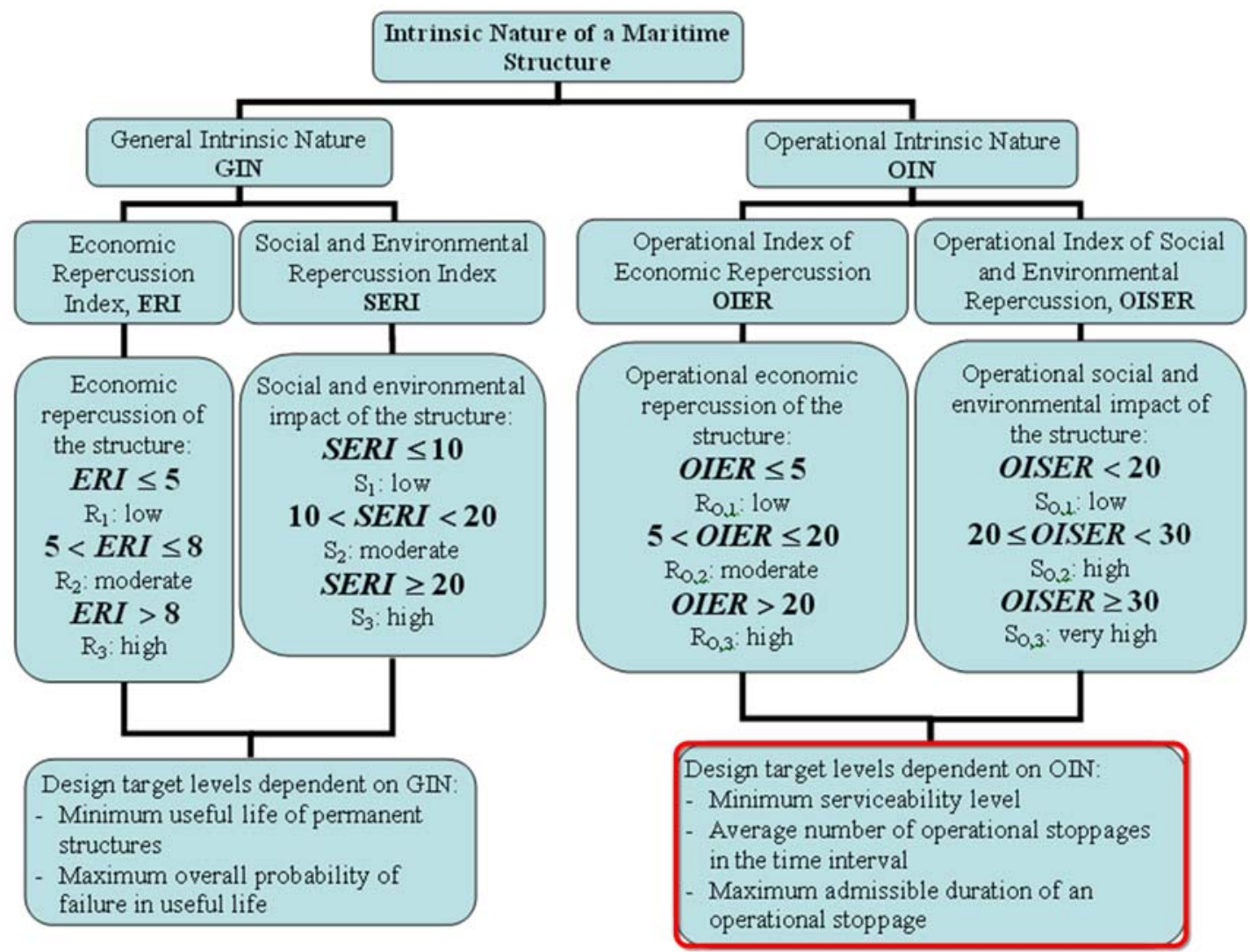

Figure 1.Intrinsic nature of a submarine outfall [Mendonça et al., 2012a].

\section{Use and Exploitation of a Structure during its Useful Life}

The exploitation of any section of a structure can be defined in terms of the following: (i) minimum levels of operationality (in a specified time period based on previous economic studies); (ii) average number of stoppages (in a time interval linked to social and environmental factors): (iii) the maximum admissible duration of a stoppage in a time interval that depends on economic factors and the cycle of demand.

\section{Minimum Operationality}

The minimum operationality of a submarine outfall (or each of its sections) depends on the consequences of a stoppage within the context of the operational stoppage limit states that can arise during the serviceability phase, as well as the average number of stoppages and maximum duration of a stoppage. For the serviceability phase, the operational nature of the structure provides an overall evaluation of these consequences. The value, however, cannot be less than the value obtained for the operational index of economic repercussion (OIER) and the operational index of social and environmental repercussion (OISER). In this sense, the structure's operationality should be greater when the economic consequences of operational stoppage are more important. During its useful life, the operationality of the structure or one of its sections in reference to the principal modes assigned to the stoppage limit states in normal working and operating conditions has to be in accordance with the OIER.

Design work and predictive studies on effluent discharge problems have to consider the physical aspects of hydrodynamic processes that determine the fate and distribution of the effluent from the discharge location, and the formulation of mixing zone regulations that intend to prevent any harmful impact of the effluent on the aquatic environment and associated uses.

\section{Average Number of Stoppages}

The average number of stoppages, defined in a given time interval (usually a year), and for those cases in which it has not already been specified, is the average number of occurrences of all modes assigned to stoppage limit states $\left(N_{\text {stop }}\right)$. 
If the operational stoppage has social and environmental repercussions, no stoppages must be allowed to occur. The submarine outfall should thus always be kept operational except in the event of extraordinary unforeseen conditions.

The main reasons that submarine outfalls stop operating are the obstruction of the pipe and diffuser, exceedance of the recommended limit values for the effluent discharge, and the use of a bypass. Bypasses can pose a direct health risk to people who come into contact with contaminated water. However, they can also indirectly affect people that consume contaminated seafood (e.g. shellfish). Such stoppages mostly occur in periods of heavy rain when the effluent exceeds the submarine outfall capacity. Information concerning bypasses can help to determine whether operations or maintenance practices need to be improved or if an upgrade of the submarine outfall is required. $N_{\text {stop }}$ is evaluated considering the exceedance of limit values for the discharge, the obstruction of the pipe or diffuser and the bypass of the effluent due to overflow.

\section{Maximum Duration of Stoppage}

During the structure's useful life (and when there are no previous specifications), the probable maximum duration of a stoppage (in hours) is based on the OIER and OISER of the affected section of the structure.

\section{LIMIT STATES AND FAILURE MODES FOR SUBMARINE OUTFALLS}

The procedure described in the ROM 0.0 (2002) specifies the overall probability of failure in the useful life of a maritime structure for all the principal modes ascribed to limit states. In Mendonça et al. (2012a) the procedure is adapted to submarine outfalls considering four representative structures in the Portuguese coast. The main failure modes regarding operational limit states are identified and described in Table 1.

Table 1. Operational failure modes for submarine outfalls [Mendonça et al., 2012b].

\begin{tabular}{|c|c|c|c|}
\hline Fallure EFfects & $\begin{array}{l}\text { Fallure } \\
\text { Modes }\end{array}$ & Causes & Root CAUSE \\
\hline Hydraulic & Pipe & $\begin{array}{l}\text { Flows that exceed outfall capacity } \\
\text { Blockage by marine growth in the upstream pipe. } \\
\text { Action by nets and solid objects. } \\
\text { Changes in effluent composition: minimum } \\
\text { velocities required for self-cleansing not } \\
\text { respected. } \\
\text { Malfunction of the self-regulating valve. } \\
\text { Air intrusion: pipe curvatures, high slopes that } \\
\text { influence additional sedimentation and air } \\
\text { accumulation. }\end{array}$ & $\begin{array}{l}\text { Improper equipment maintenance } \\
\text { Design deficiency } \\
\text { Changes in effluent composition } \\
\text { Poor control procedures }\end{array}$ \\
\hline Hydraulic & $\begin{array}{c}\text { Diffuser } \\
\text { Clogging/ } \\
\text { Obstruction }\end{array}$ & $\begin{array}{l}\text { Blockage caused by marine growth or greasy } \\
\text { substances around and inside the diffuser } \\
\text { reducing partly or totally the flow section. } \\
\text { Sea water intrusion. }\end{array}$ & $\begin{array}{l}\text { Improper equipment maintenance } \\
\text { Poor control procedures } \\
\text { Low flux periods } \\
\text { Sea water and effluent density } \\
\text { differences }\end{array}$ \\
\hline Hydraulic & \begin{tabular}{c|} 
Risers \\
Obstruction
\end{tabular} & Blockage by marine growth or greasy substances. & $\begin{array}{l}\text { Improper equipment maintenance } \\
\text { Poor control procedures }\end{array}$ \\
\hline \multirow[t]{2}{*}{ Environmental } & $\begin{array}{l}\text { Inefficient } \\
\text { Plume } \\
\text { Dispersion }\end{array}$ & $\begin{array}{l}\text { Insufficient dilution, insufficient dispersion. } \\
\text { Offensive matter in effluent. } \\
\text { Effects of currents and wind. }\end{array}$ & $\begin{array}{l}\text { Design deficiency } \\
\text { Installation errors } \\
\text { Improper equipment maintenance } \\
\text { Poor monitoring measures }\end{array}$ \\
\hline & $\begin{array}{c}\text { Exceedance } \\
\text { of Legislated } \\
\text { Values }\end{array}$ & $\begin{array}{l}\text { Extreme events (e.g. high rainfall). } \\
\text { Effects of currents and wind. }\end{array}$ & $\begin{array}{l}\text { Poor monitoring measures } \\
\text { Design deficiency } \\
\text { Improper equipment maintenance }\end{array}$ \\
\hline Hydraulic & \begin{tabular}{c|} 
Manholes \\
Surcharging
\end{tabular} & $\begin{array}{l}\text { Supercritical velocities } \rightarrow \text { hydraulic jumps } \rightarrow \\
\text { pipes flowing full }\end{array}$ & Design deficiency \\
\hline Hydraulic & $\begin{array}{c}\text { Buoyancy } \\
\text { due to } \\
\text { Liquefaction }\end{array}$ & $\begin{array}{l}\text { When soil liquefies, it behaves like a thick fluid; } \\
\text { the pipe embedded in it will be subjected to the } \\
\text { buoyant force from below. }\end{array}$ & Design deficiency \\
\hline
\end{tabular}

This study focus on the environmental failure effects of submarine outfalls related to the inefficient plume dispersion. The environmental values considered are aquatic ecosystem and recreational activities (including aesthetics).

Preservation of satisfactory levels of quality in coastal waters, tied to ecological and health considerations, must account for the risk that the pollution of such waters represents for animal and plant species living in the sea, and for man through his use of the marine environment (bathing) and its products (consumption of marine animals).

The risk that populations may incur from marine pollution comes primarily from two "uses" of the sea, i.e. bathing and consumption of sea products (especially if they are consumed raw, which relates mainly to consumption of shellfish). Therefore, regulations are generally formulated as two series of standards concerning "bathing" and "shellfish culture" and are based on the maximum content of seawater pollutants at levels which are considered acceptable in terms of these two risks [UNEP-MAP, 2004]. 
The high variability of marine conditions means that sustainable and efficient management of the outfall must be also available for these conditions.

A methodology is proposed that aims to introduce a sufficient safety margin in the structure design and operationality preventing inefficient plume dispersion and its social, environmental and economic effects.

\section{PREDICTIVE STUDIES ON EFFLUENT DISCHARGE}

The presence or absence of certain agents and their possible effect on the submarine outfall depend on the site, subset, structure typology, and time interval involved. The parameters or environmental characteristics to be considered or studied in the design and installation of these structures include [UNEP-MAP, 1996]:

a) Characteristics needed for outfall construction:

- Topography and bathymetry;

- Bottom materials and morphology;

(b) Characteristics needed for setting the water quality objectives:

- Openness of the coast;

- Activities and sewage discharges in a sector around the selected outfall siting and sensitive areas in this sector;

(c) Parameters needed for the calculation of the efficiency of the outfall:

- Predominant surface currents and wind patterns;

- Wastewater flow and contaminant load;

(d) Other parameters:

- Continuous current measurements;

- Dispersion coefficients;

- $\mathrm{T}_{90}$ for faecal coliforms and faecal streptococci;

- Temperature profile and benthic populations.

The developed methodology, depicted in Figure 2, considering the above parameters focus on three main aspects:

o Accomplish the environmental limitations established in Portuguese and EU Directives [Mendonça et al., 2012b];

o Provide a probabilistic approach of the project of submarine outfalls, implementing a Monte

Carlo simulation methodology that considers climatic variability and mid long term trends;

o Implement procedures to predict plume temporal and spatial variability (yearly).

The methodology will allow verifying/adapting the design operational target levels defined in Mendonça et al. (2012a) and analyzing management strategies and their consequences for loss of operationality applying multi-criteria assessment.

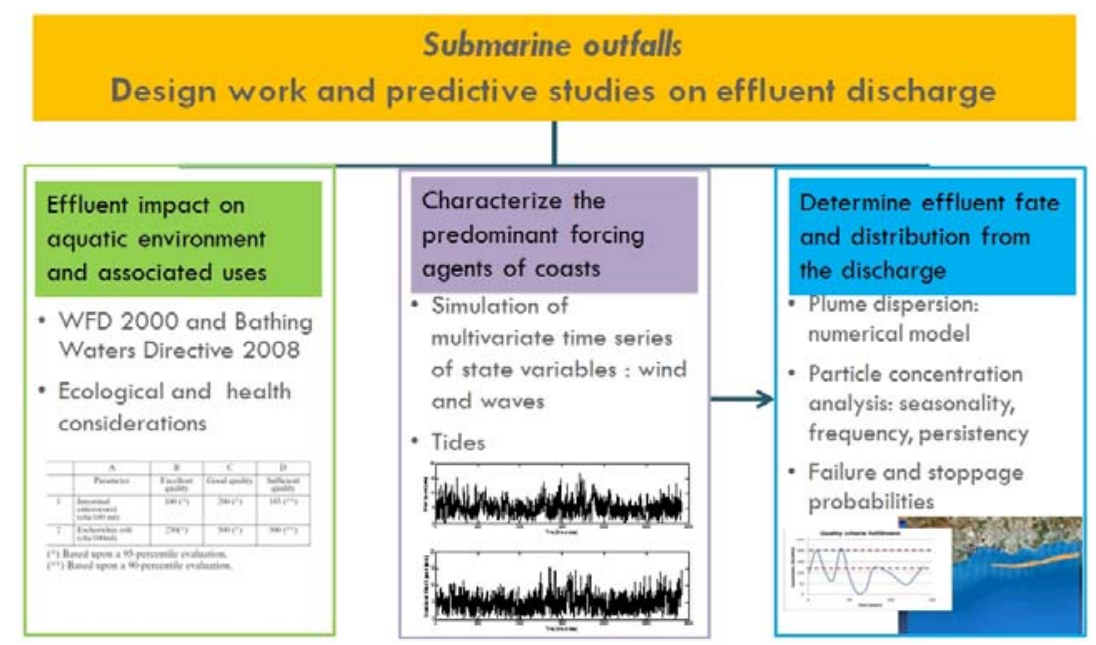

Figure 2. Developed methodology scheme. 


\section{Legislative Framework}

The Water Framework Directive sets the goal of achieving a "good status" for all of Europe's surface waters and groundwater by 2015 (at least 40\% of the EU's surface water bodies are at risk of not meeting the 2015 objective) [European Union, 2010].

Instruments for water resource management have an important role in preventing water-related conflicts, through assessing the resource's spatial and temporal variability on coastal areas. It is therefore important to follow the water policy in order to promote more adequate land use and better protection of water quality and associated ecosystems. The design of submarine outfalls is tied to:

-Exceedance of threshold values: related to agents of the physical environment (climatic agents);

-Unacceptable environmental effect or social repercussion: Stoppage modes carried out to avoid damage to people, historical and cultural heritage, and environment;

-Legal constraints: Stoppage modes carried out to fulfil legal requirements.

According to the legislative framework submarine outfall monitoring focuses on eight critical stressors/constituents: salinity, pathogens, nutrients, turbidity, heavy metals, natural and organic material, hydrocarbons and pesticides. These eight constituents can be evaluated within the context of four different environmental measurement areas: effluent, water column, sea floor environments, and fish and shellfish.

\section{Forcing agents simulation}

For modeling the effluent fate it is required to have the boundary conditions that force the hydrodynamic model. After the astronomical tide, that is a deterministic variable, the main forcing agent is the wind. Then, for applying the probabilistic verification and design procedure proposed in this work it is necessary to implement a Monte Carlo simulation methodology for wind time series, accounting for both wind speed and wind direction.

In this work a simulation methodology is proposed that is based on the use of mixture nonstationary distributions for deseasonalization of the data, and a combination of copula-based and autoregressive models for modeling auto and crosscorrelation of the series. The proposed methodology is based on Solari and Losada (2011) and is summarized as follows:

-Wind speeds are fitted with a parametric probability distribution function. For this a nonstationary mixture model is used, composed of a truncated two-parameter Weibull distribution for the main-mass of the data and a generalized Pareto distribution (GPD) for the upper tail (see Solari and Losada, 2011, 2012a, 2012b).

-A copula-based model is used for modeling the autocorrelation of the deseasonalized wind speed time series. For the deseasonalization the Weibull-GPD model is used (see Solari and Losada, 2011).

-Wind directions are fitted with a parametric model devised for circular variables (see e.g. Fisher, 1993). In this case a non-stationary mixture model composed by two Wrapped Student-t distributions is used (a detail description of this kind of distribution is presented in Solari and Losada (2012c), though they use a mixture of Wrapped Normal distributions).

-Fitting an autoregressive model for the deseasonalized wind directions, using deseasonalized wind velocities as an exogenous variable (ARX model).

Once the four described models are fitted to the original data set, new time series are simulated. For this, wind speed time series are simulated first, using the copula-based dependence model and the Weibull-GPD distribution. Then, wind directions time series are simulated conditional to the wind speed time series previously obtained, using in this case, the ARX model and the mixture of wrapped distributions.

For applying the proposed simulation methodology a hindcast wind time series is used. The data were provided by the Spanish Port Authorities (Puertos del Estado) and correspond to a grid node located in the Atlantic Ocean next to Faro, Portugal (WANA point number 1050048).

Figure 3 shows empirical and modeled non-stationary probability distributions for speeds and directions. It is noticed that the proposed model provides a good fit to the data. In regards to auto and crosscorrelation, results presented in Figure $\mathbf{4}$ show that autocorrelation of the simulated series is in good agreement with the autocorrelation of the original series. On the other hand agreement between original and simulated crosscorrelations is not as good as expected. However, given the low values taken by the crosscorrelation of the original data series, no further analysis is performed. Finally, Figure 5 shows stretches of the original and simulated wind speed series. 

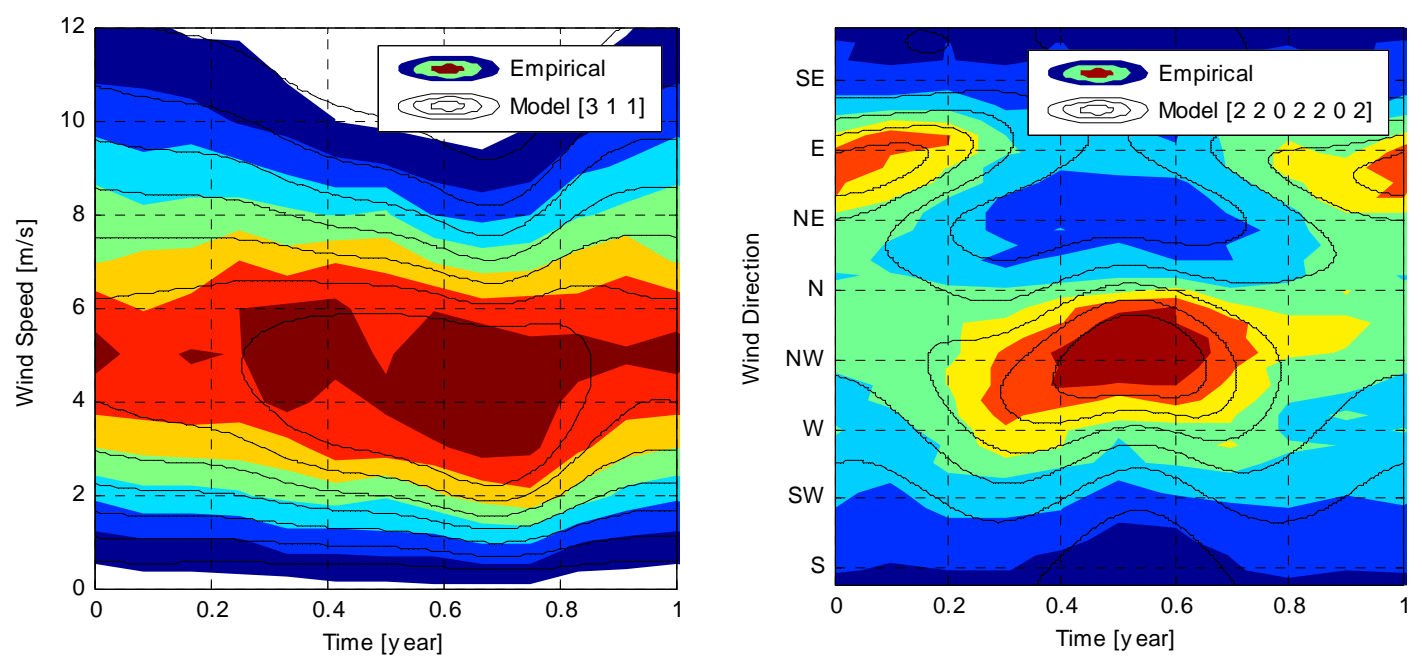

Figure 3. Empirical (filled color contours) and modeled (black lines) mean annual non-stationary probability density function for wind velocity (left) and wind direction (right).
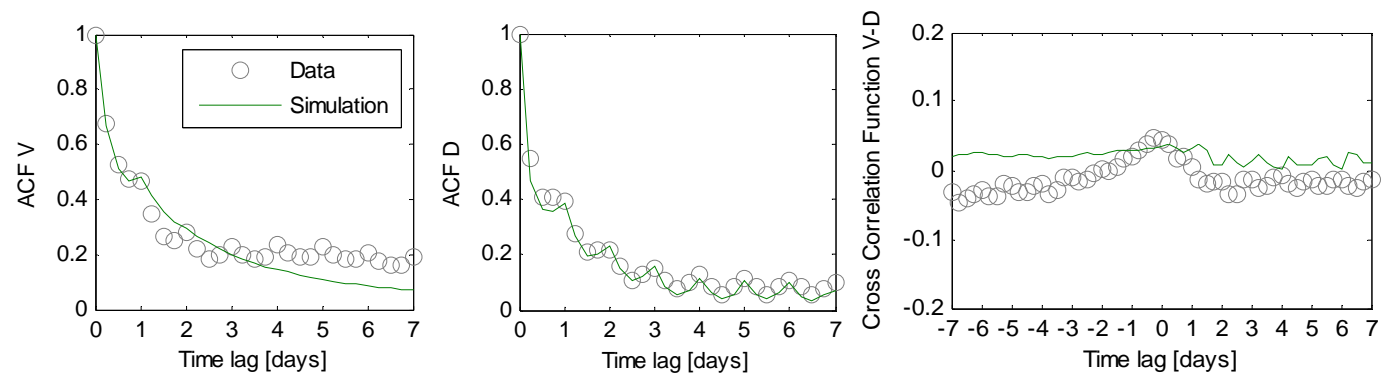

Figure 4. Autocorrelation and crosscorrelation of wind speed and direction estimated from the original data series (grey dots) and from the simulated series (green lines).
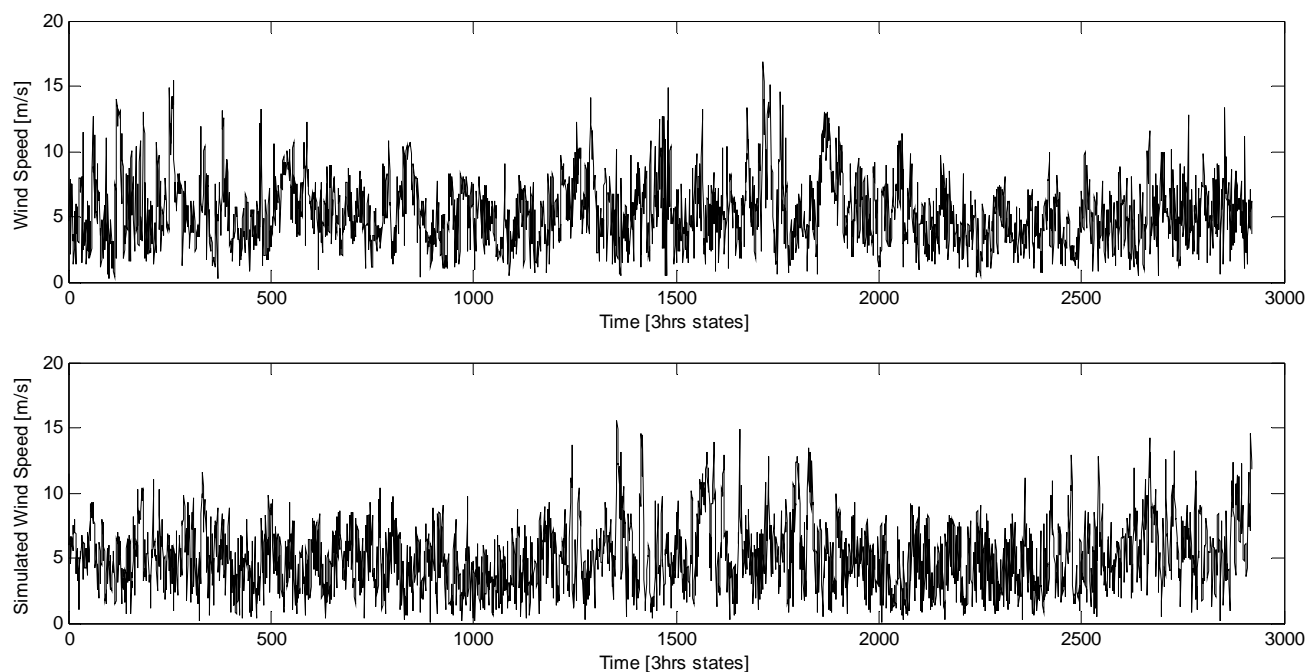

Figure 5. Original (top) and simulated (bottom) wind speed time series.

\section{Effluent fate and distribution from the discharge}

The numerical modeling process uses TELEMAC [Galland et al., 1991], developed by the National Hydraulics and Environment Laboratory of the Research and Development Directorate of the French Electricity Board in collaboration with other research institutes.

TELEMAC contains in particular the TOMAWAC module [Benoit et al., 1996] for calculating the wave propagation and the TELEMAC 2D module [Hervouet and Bates, 2000] for calculating the hydrodynamics. 
The TELEMAC-2D code solves depth-averaged free surface flow equations as derived first by Barré de Saint-Venant in 1871. The main results at each node of the computational mesh are the depth of water and the depth-averaged velocity components. TELEMAC-2D is able to take into account, among others, the following phenomena: propagation of long waves, including non-linear effects, friction on the bed, the effects of meteorological phenomena such as atmospheric pressure and wind, turbulence, influence of horizontal temperature and salinity gradients on density, entrainment and diffusion of a tracer by currents, including creation and decay and sink terms, particle tracking and computation of Lagrangian drifts, inclusion of wave-induced currents (by link-ups with the ARTEMIS and TOMAWAC modules), coupling with sediment transport [Mensencal, 2012].

The main goals of implementing TELEMAC are: (i) to simulate 1000 statistically independent events (yearly) scenarios in feasible computation times, using simulated wind time series as boundary conditions, while (ii) representing the typical annual wave-current conditions.

\section{Multi-criteria assessment for design}

Once the environmental agents and their actions exceed a certain magnitude, the submarine outfall should stop operating to avoid damage themselves, the user or the physical environment. Once the agent or its action falls below the threshold value, the service may be resumed.

Operational limit states, therefore, do not cause damage to the maritime structure, but are established to avoid this occurring. The operational limit states evaluate the exploitation and management conditions of the structure, and thus should be analyzed and evaluated in the design phase.

It is advisable to draw up a User and Operations Manual for the structure to inform the technician responsible for the operational limit states and stoppage modes [ROM 0.0, 2002].

Submarine outfalls are designed to prevent the pollution of bathing waters and the capacity of these structures is directly related with the probability of incompliance with the water quality criteria. The developed methodology analyses the plume behaviour in each time interval (yearly) with the objective to:

$>$ Calculate the probability of exceeding a representative threshold value whose occurrence may be significant to the operationality of the structure (e.g. faecal coliform concentration);

$>$ Calculate the persistence of the exceedance of that threshold value;

$>$ Calculate the frequency and seasonality;

$>$ Identify the areas with high probability of the exceedance of that threshold value;

$>$ Establish a relation between wind forcing and surface currents, finding out if the spatial variability of plumes is primarily determined by atmospheric forcing;

$>$ Quantify the physical forcing mechanisms that govern the variability of plumes in the studied coastal system and

$>$ Define the plume distribution function and its lower and upper characteristic levels.

Project design alternatives for submarine outfalls should be drawn based on these result analyses with solutions flexible enough to be constantly upgraded and improved in order to fulfill expected environment protection requirements as the Marine Strategy Framework Directive and established target design levels of operationality.

\section{STUDY SITE}

To illustrate the procedure, an application to the submarine outfall of Vale de Faro, situated in Praia do Inatel, Albufeira, in the south coast of Portugal is analysed. The south of Portugal is a region sheltered from the most dominant and important swell source, the North Atlantic. Besides the long travel distance involved, storms generated in the North Atlantic have to circumvent the southern Portuguese continental shelf to reach the coast (Figure 6). These factors contribute to an important dissipation of storm energy and wave height, which can consequently introduce different patterns into storm variability. The local storm wave climate is also influenced from the southeast by stormy waves originating in the Gibraltar Strait region [Almeida et al., 2011].

These site-specific characteristics and their possible effect on storminess are studied in order to perform simulation of multivariate time series of the state variables that characterize the local predominant forcing agents. Historical and climatic information of physical oceanographic parameters (waves, tides, currents, winds, etc.) is available through the Spanish Port Authorities 
(www.puertos.es). The case study used time series of WANA point number 1050048 (Figure 6b). The nearest point to Vale de Faro is point number 1047048 and should be used in the study progression although the wind characteristics are expected to be similar.

\section{Vale de Faro submarine outfall}

Albufeira, in the south of Portugal, has 40828 inhabitants that triplicate due to tourism around the summer season.

The submarine outfall of Vale de Faro was selected to represent a common type of submarine outfall in Portugal, based on the type of effluent (urban) and importance to the region in terms of tourism and municipal serviceability, Figure 6.

The submarine outfall, installed in 1986, became under designed due to increasing number of tourists in the summer season and a new structure was proposed and constructed in 2002. These structures have been monitored and supervised regarding wastewater and environmental characteristics (e.g. topography and bathymetry, bottom materials and morphology) and the description of important and minor failures that have occurred. The system supplies sanitation to about 130000 P.E:, disposing an urban effluent with secondary treatment, plus disinfection in summer. The HDPE outfall is $1020 \mathrm{~m}$ long, with a $1000 \mathrm{~mm}$ diameter and discharging at $11 \mathrm{~m}$ depth (datum level). The diffuser has 32 ports and is $160 \mathrm{~m}$ long.

The submarine outfall was designed to prevent the pollution of bathing waters and the capacity of the submarine outfall is directly related with the probability of incompliance with the water quality criteria.

The aim is to describe the plume behaviour and coliform concentration in touristic and sensitive areas, near Albufeira, in the summer and winter periods.

The hydrodynamic model (TELEMAC) is forced with astronomical and meteorological tides at the oceanic boundary (Le Provost Database) and wind velocity and wind direction on the ocean.

a)

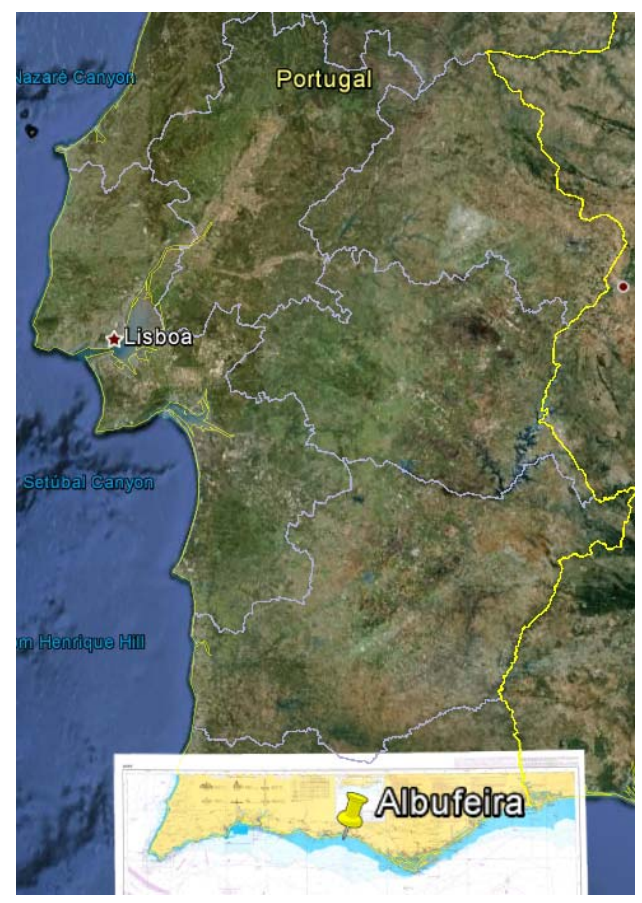

b)

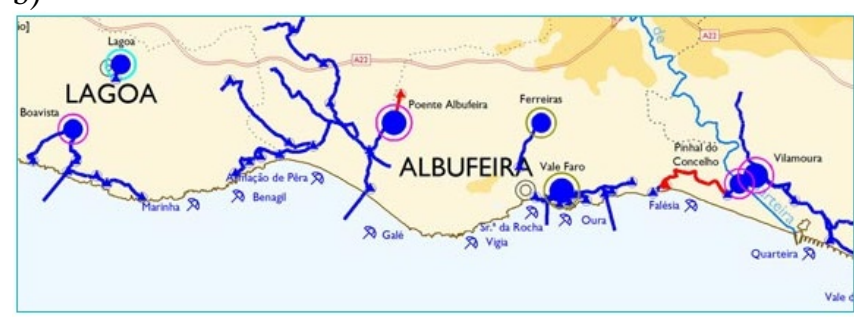

c)

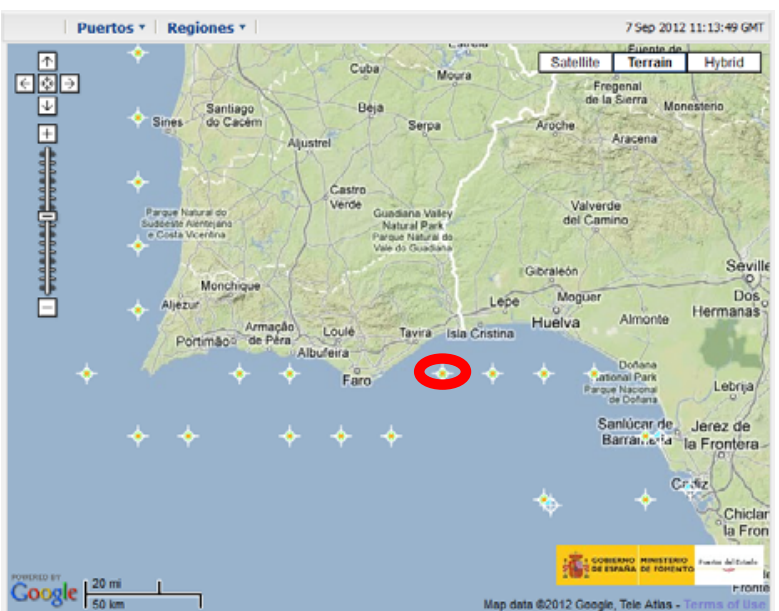

Figure 6. a) Case study area; b) Vale de Faro submarine outfall; c) Puertos del Estado: Point 1050048 (source: www.puertos.es).

Control points/areas are selected based on their importance to human activities and protected areas. The analysis of results focus on coliform concentration along time considering the limits established in the Water Framework Directive. Spatial attention is given to the probability of exceeding the coliform concentration value whose occurrence may be significant to the operationality of the structure; persistence of the exceedance of that threshold value; and calculation of the frequency and seasonality. 
Moreover, spatial and temporal variability of the water quality (based on coliform concentration) in important/sensitive areas is analysed. Figure 7a presents an example of the plume beahaviour for Vale de Faro submarine outfall where its proximity to the coast and beach is observed. In Figure 7b quality criteria fulfillment (faecal coliform concentration) for 150 years period is exemplified.
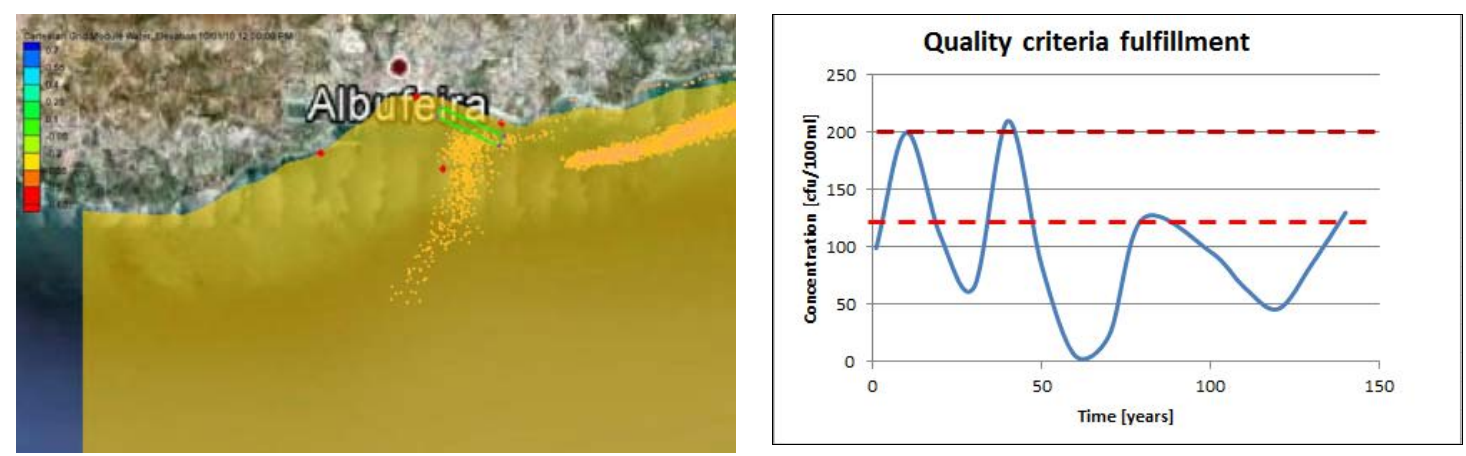

Figure 7. Vale de Faro submarine outfall: effluent transport near the coastline.

\section{CONCLUSIONS AND FUTURE WORK}

A risk assessment procedure is proposed for operational limit states based on three main topics: environmental legislative framework, probabilistic assessment for the definition of climate agents on the coastline and effluent fate and distribution.

The methodology results are expected to help identifying the structure's probability of failure or stoppage and the definition of operational target design levels enabling decision on project design alternatives. The development of a formal optimization procedure for the design of submarine outfalls is done through multi-criteria decision analysis.

The outcome allow obtaining optimal yearly failure rates for different modes of failure and a rational and systematic procedure for the optimal design of submarine outfalls supporting the decision for management.

The methodology can be implemented as a real time or short term forecast tool estimating the failure probability before it takes place and as a decision support tool. Forecast of intense and episodic rainfall events that can produce flood events of relatively large volume and short duration could be another interesting forcing to be considered. These flood events are of great interest to coastal residents, resource managers, and researchers as they provide a rapid and direct mechanism for the transport of anthropogenic materials into coastal and bay systems and collectively have a greater area of influence [DeCarlo et al., 2004].

\section{ACKNOWLEDGMENTS}

The writers wish to thank the financial sponsorship of Ana Mendonça by Fundação para a Ciência e a Tecnologia, Portugal, through her PhD grant SFRH / BD / 60748 / 2009. The writers also gratefully acknowledge the technical support provided by WW - Consultores de Hidráulica e Obras Marítimas, S.A., Portugal.

\section{REFERENCES}

Almeida, L.P., Ferreira, Ó., Vousdoukas, M., Dodet, G. (2011). "Historical Variation and Trends in Storminess along the Portuguese South Coast.” Natural Hazards and Earth System Sciences, 11, 2407-2417.

Benoit, M., F. Marcos and F. Beck (1996). "Development of a third generation shallow-water wave model with unstructured spatial meshing.” pp.465-478. In: Proc. 25th Int. Conf. on Coastal Eng. (ASCE). Orlando, Florida, USA.

DeCarlo, E.H., V.L. Beltran, and M.S. Tomlinson (2004). “Composition of water and suspended sediment in streams of urbanized subtropical watersheds in Hawaii.” Applied Geochemistry 19 (7):1011-1037.

European Union (2010). "Water is for life: How the Water Framework Directive helps safeguard Europe's resources.” Publications Office of the European Union. ISBN 978-92-79-13538-5, doi 10.2779/83017.

Fisher, N.I. (1993). “Statistical analysis of circular data.” Cambridge University Press. 
Galland, J.C., Goutal, N., Hervouet, J.M. (1991). “TELEMAC: A New Numerical Model for Solving Shallow Water Equations.” Advances in Water Resources AWREDI, Vol. 14, No. 3, pp. 138-148.

Grace, R.A. (2009). "Marine Outfall Construction Background, Techniques, and Case Studies." American Society of Civil Engineers. ISBN-10: 0784409846 (1991).

Hervouet, J.-M. and Bates, P. (2000). "The TELEMAC modelling system Special issue." Hydrol. Process, 14: 2207-2208. doi: 10.1002/1099-1085(200009)14:13<2207::AID-HYP22>3.0.CO;2-B.

Losada, A. Miguel and Benedicto, M. Izaskun (2005). “Target Design Levels for Maritime Structures”. J. Waterway, Port, Coastal, and Ocean Eng. 131, pp. 171-180.

Mendonça, A., Losada, M.A., Reis, M.T.; Neves, M.G. (2012a) "Risk Assessment in Submarine Outfall Projects: the Case of Portugal.” Journal of Environmental Management (in press).

Mendonça, A., Losada, Neves, M.G. and Reis, M.T. (2012b) "Operational forecast methodology for submarine outfall management: application to a Portuguese case study.” MWWD \& IEMES 2012 $7^{\text {th }}$ International Conference on Marine Wastewater Discharges and Coastal Environment, Montenegro, 21-16 October.

Mensencal, Y. (2012). "Use of TELEMAC software system as a technical modelling tool for coastal zone development studies.” SOGREAH Eau - Energie - Environnement - SPICOSA project.

ROM 0.0 (2002). "General Procedure and Requirements in the Design of Harbor and Maritime Structures. Part I: Recommendations for Maritime Structures”, Ministerio de Fomento, Puertos del Estado, Spain. ISBN 84-88975-30-9.

Solari, S., and M.A. Losada (2011). "Non-stationary wave height climate modeling and simulation.” Journal of Geophysical Research, Vol. 116, C09032, doi:10.1029/2011JC007101.

Solari, S., and M.A. Losada (2012a). "Unified distribution models for met-ocean variables: Application to series of significant wave height.” Coastal Engineering, Vol. 68, 67-77, doi:10.1016/j.coastaleng.2012.05.004.

Solari, S., and M.A. Losada (2012b). “A unified statistical model for hydrological variables including the selection of threshold for the peak over threshold method." Water Resources Research (Accepted manuscript)

Solari, S. and M.A. Losada (2012c). "Parametric and non-parametric methods for the study of the variability of wave directions: application to the Atlantic Uruguayan coasts.” Proceedings of the 33th International Conference on Coastal Engineering.

UNEP-MAP: United Nations Environment Programme-Mediterranean Action Plan (1996). "Guidelines for Submarine Outfall Structures for Mediterranean Small and Medium-Sized Coastal Communities.” Athens. UNEP(OCA)/MED WG.104/Inf.7.

UNEP-MAP: United Nations Environment Programme-Mediterranean Action Plan (2004). "Guidelines on sewage treatment and disposal for the Mediterranean region." Athens. MAP Technical Reports Series No. 152. 